\title{
Doilies Digitais: Um Estudo da Aplicação de Criatividade Computacional ao Crochê
}

Marília Lyra Bergamo é Professora Adjunta do Departamento de Desenho da Escola de Belas Artes da Universidade Federal de Minas Gerais (UFMG). Sua pesquisa tem ênfase em Arte e Tecnologia, Sistemas Complexos e Design para mídias interativas, atuando principalmente nos seguintes temas: arte computacional, design de interação, e criação de interfaces multimodais. Atuante no grupo/laboratório 1maginari0: Poéticas Computacionais da Universidade Federal de Minas Gerais.

<marilialb@eba.ufmg.br > ORCID: 0000-0001-9105-7886
Resumo Neste artigo descrevemos o que são os doilies e apresentamos algumas das ferramentas digitais de criação de padrões gráficos para o crochê. Constatamos que as ferramentas digitais, disponíveis durante o desenvolvimento deste trabalho, não incorporam efetiva criatividade computacional. Isto posto, esse artigo então apresenta a aplicação de lógicas computacional ao desenvolvimento do padrão para doilies de crochê e argumenta iminentes possibilidades de incorporação de criatividade computacional para a geração destes. A incorporação desses sistemas criativos dá se pela gradual atribuição de autonomia aos processos computacionais envolvidos e a relação que o artesão estabelece com estes, o resultado dessa interação influencia diretamente a emergência desses padrões. As relações entre o artesão e os sistemas criativos manifestam-se em um ecossistema de produção, e este artigo finaliza discutindo as potencialidades da incorporação de criatividade computacional para o design de doilies.

Palavras chave Arte e Tecnologia, Design, Algoritmos, Criatividade Computacional. 
André Luiz Silva é graduado em Arquitetura e Urbanismo com estudos complementares em Design. Atualmente é bolsista da CAPES no Programa de Pós-Graduação em Artes da Escola de Belas Artes da UFMG. Possui interesse em metodologias de projeto, projeto assistido por computador, técnicas tradicionais e tecnologia digital direcionada ao desenvolvimento de arquitetura, produto e arte.<andrearqurb@outlook.com>

ORCID: 0000-0002-4984-4912

\section{Digital Doilies: A Study of the Application of Computational Creativity to Crochet}

Abstract In this article we describe what doilies are and present some of the digital tools for creating graphic patterns for crochet. We found that the digital tools, available during the development of this work, do not incorporate effective computational creativity. That said, this article then presents the application of computational logic to the development of the pattern in doilies for crochet and argues imminent possibilities of incorporating computational creativity for the generation of these. The incorporation of these creative systems is due to the gradual attribution of autonomy to the computational processes involved and the relationship that the craftsman establishes with them, the result of this interaction directly influences the emergence of these patterns. The relations between the craftsman and the creative systems are manifested in a production ecosystem, and this article ends by discussing the potentialities of incorporating computational creativity into the design of doilies.

Keywords Art and Technology, Design, Algorithms, Computational Creativity.

Doilies Digitales: Un estudio de la aplicación de la creatividad computacional al crochet

Resumen En este artículo describimos qué son los doilies y presentamos algunas de las herramientas digitales para crear patrones gráficos para crochet. Descubrimos que las herramientas digitales, disponibles durante el desarrollo de este trabajo, no incorporan una creatividad computacional efectiva. Dicho esto, este artículo presenta la aplicación de las logicas computacionales para el desarrollo del patrón para doilies de crochet y argumenta posibilidades inminentes de incorporar la creatividad computacional para la generación de estos. La incorporación de estos sistemas creativos se debe a la atribución gradual de autonomía a los procesos computacionales involucrados y la relación que el artesano establece con ellos, el resultado de esta interacción influye directamente en la aparición de estos patrones. Las relaciones entre el artesano y los sistemas creativos se manifiestan en un ecosistema de producción, y este artículo termina discutiendo las potencialidades de incorporar la creatividad computacional en el diseño de doilies.

Palabras clave Diseño, Enseñanza de fotografía, Tecnologías Digitales de Información y Comunicación, Estudio prospectivo. 


\section{Doilies e o Crochê}

Etimologicamente a palavra crochê foi originada de um termo existente no dialeto nórdico, $k r o k r$, que significa gancho, assim como no francês medieval, croké, termo usado para definir um instrumento de ferro recurvado que permitia suspender ou segurar algo. Na prática, o crochê produz uma renda que possui características que a difere de outros tipos de tecido. Ela não possui função utilitária significante e é prioritariamente utilizada para decorar. A liberdade causada pela falta de propósito utilitário poderia justificar uma exploração dos padrões de crochê, através das suas qualidades formais ou valores estéticos, porém, os artesãos têm primordialmente reciclado padrões de renda de crochê e mudanças significativas não são observadas em mais de 500 anos (Kenning, 2009).

A fabricação da peça de crochê envolve a manipulação de um fio único e contínuo através de uma agulha de metal, madeira ou osso, e a técnica pode ser empregada na fabricação de tecidos para vestuário, decoração e até itens funcionais. Acredita-se que a história da técnica evoluiu do bordado e suas variações, e o crochê como é conhecido hoje em dia tem por volta 200 anos de idade (Kenning ,2009). Com o surgimento da técnica de crochê, os artesãos perceberam que novos padrões de desenhos poderiam ser criados, assim como, padrões feitos em técnicas que consumiam muito tempo como por exemplo, renda de bilros, pontos venezianos e bordados poderiam ser mais rapidamente reproduzidos. Contudo, críticas sugerem que a renda de crochê não era considerada renda de verdade, isso por que a técnica era empregada primordialmente para copiar outras técnicas e não para criar novos padrões, e também porque as rendas de crochê geralmente apresentam poucos espaços vazios e transparências, já que ela incorpora menos espaço em seus desenhos. Percebe-se que o crochê vem de encontro aos fazeres poéticos onde a reprodutibilidade e a repetição criam uma tensão entre criação e concretização da técnica, onde criatividade e função reprodutiva são codependentes e entrelaçadas. Apesar das circunstâncias, a renda de crochê é popular e altamente valorizada e a técnica acabou se tornando uma atividade comumente utilizada para criar padrões de renda geralmente circulares chamados de doilies que inicialmente possuíam a função de porta copos. Os doilies são utilizados para proteger móveis de manchas de copos e pratos. Geralmente pequenas peças circulares eram unidas para criar peças maiores como cobertores ou forro de mesa (Kenning ,2009).

Em termos de desenvolvimento de padrões, os padrões de crochê são materializados através de uma série de regras que subscrevem a criação dos padrões de renda, essas regras estão relacionadas com o modo em que a linha é envolvida pela agulha de crochê, os tipos de pontos, os módulos de padrões e a forma do padrão. Padrões de crochê são algorítmicos e isso significa que eles podem existir conceitualmente como um conjunto de processos em que as ações envolvidas na construção de um padrão podem ser estabelecidas antes do padrão se materializar fisicamente. Outra caracte- 
rística dos padrões de crochê é a iteratividade. Embora todos os padrões de crochê não sejam iterativos, grande parte dos desenhos são construídos a partir de um processo iterativo, logo, as mesmas ações podem ser aplicadas repetidamente a partir do ponto de início até o fim do padrão. É interessante perceber que os padrões de crochê não existem somente como formas físicas, mas também como código. As receitas de crochê muito veiculadas em revistas de artesanato, são um conjunto de instruções verbais do padrão que quando abreviadas, se transformam em uma sintaxe que inclui repetições de ciclos e módulos. Essa sintaxe é paralela ao desenvolvimento de programação em computadores, uma vez que, as instruções do padrão contidas na sintaxe funcionam como um código a ser interpretado pelo artesão (Kenning ,2009).

Quando trabalhada no ambiente digital a técnica de crochê pode ganhar algumas oportunidades para a sua exploração. $O$ foco pode ser removido do objeto físico e ser reposicionado no processo de desenvolvimento dos padrões. $O$ padrão de crochê pode se transformar num híbrido de influência humana e tecnológica, e ser influenciado não apenas por decisões subjetivas do artesão, mas pelo fluxo de informação dos scripts e sistemas operacionais, e o ambiente digital pode lidar com algoritmos complexos e permitir que grandes processos iterativos aconteçam de forma mais rápida e efetiva, permitindo que grandes números de padrões sejam criados, sofram mutações e sejam observados (Kenning ,2009).

\section{Softwares de Criação de Doilies}

A primeira observação sobre a criação dos doilies é o fato de serem construídos por carreiras. Cada carreira possui um padrão de pontos simétricos e uniformes, a simetria e uniformidade da peça é mantida mesmo quando mais de um tipo de ponto é utilizado na mesma carreira. Essa é a lógica dos softwares de criação digital de Crochê para doilies, faremos aqui uma argumentação de três alternativas disponíveis até a data de produção desse texto.

O MyCrochet é um software que permite a criação de peças gráficas de crochê e possui funções que vão da definição do grid a ser trabalhado ao agrupamento de pontos complexos já pré-definidos. Para iniciar os trabalhos dentro do software é necessário definir a área de trabalho. A janela de configuração do grid permite alterar a dimensão horizontal, altura do esquema em pixels, o tamanho do grid em pixels e o formato do grid, podendo ser circular, quadriculado ou sem grid. Além das funções comuns, o software apresenta uma grande variedade de pontos individuais, dos mais simples aos mais complexos, assim como, uma grande variedade de pontos complexos que são os agrupamentos de pontos individuais.

O funcionamento do programa consiste em selecionar os pontos de interesse e aplicá-los ao grid. o posicionamento dos pontos acontece pelo manuseio do mouse ao clicar no grid, segurar e definir a escala do ponto 
através de uma linha de referência que aparece na tela. Alguns dos recursos do programa permite a manipulação de grupos de pontos e até a repetição de ações semelhantes. É possível agrupar os pontos e reproduzi-los até alcançar o resultado almejado. Cabe ao usuário definir a melhor estratégia para construir seu padrão gráfico. Em termos de interface, o software apresenta uma interface limpa e organizada, porém, a grande quantidade de funções requer um certo tempo para conseguir utilizar o software com facilidade, e algumas funções como girar em círculo, requer um certo entendimento sobre coordenadas cartesianas. O programa deixa o usuário livre no momento de criar o padrão gráfico, não pré estabelecendo limites como tamanhos e proporções das representações gráficas dos pontos e não limitando a área de trabalho apenas ao grid estabelecido no início do programa.

Stitchworks Software é um software livre desenvolvido por Brian Milco que permite o desenho de padrões gráficos de crochê através do posicionamento de pontos ou geração rápida de linhas ou círculos básicos. 0 software não limita o tamanho do gráfico e a contagem de pontos utilizados na peça, e permite que pontos e cores de legendas sejam customizados. O software possui uma biblioteca de pontos customizáveis que podem ser agrupados em um único elemento e alterados de acordo com a escala desejada pelo usuário.

O software oferece a possibilidade de trabalhar sem grid, com grid circular, quadriculado ou triangular. Quando o grid se encontra ativado o software apresenta uma restrição referente ao posicionamento dos pontos que só podem ser posicionados nos pontos de interseção das linhas do grid, quando a opção sem grid é selecionada, os pontos podem ser movidos de acordo com o interesse do usuário. Existe a possibilidade de rotacionar, redimensionar e reposicionar todos os pontos. Também existe a possibilidade de pré-definir os grids já preenchidos com pontos configurados previamente. Nesta opção, ao criar o grid o software permite definir o número de linhas e o espaçamento entre elas, assim como, a quantidade de pontos e modelo que irão preencher as linhas. Caso o grid escolhido seja uma peça circular, o software permite definir o número de carreiras, o espaçamento entre a carreiras, a quantidade de pontos na carreira inicial, a quantidade de pontos que aumenta em cada carreira subsequente e qual ponto irá preencher as linhas. Se a escolha for trabalhar sem grid, apenas uma tela em branco emerge. Apesar das possibilidades de autogeração de grids já preenchidos por pontos, o programa não oferece potencial randômico ou generativo, todo o procedimento acontece a partir do posicionamento individual de pontos, ou através de agrupamentos de pontos e reprodução dos mesmos.

SymblCro é um software desenvolvido por New Hampshire Software. $\mathrm{O}$ software quando iniciado coloca dois painéis de trabalho à disposição do usuário. No painel da esquerda o usuário trabalha com o gráfico a ser produzido, e no da direita ele escreve as instruções verbais para a materialização da peça, também conhecidas como receitas de crochê. Para construir o padrão gráfico o usuário pode adicionar linhas e pontos de crochê através 
de cliques no mouse e comandos do menu. Os pontos podem ser acrescentados individualmente ou em grupos uniformemente ao longo da linha ou círculo. Agrupamentos de elementos do gráfico podem ser selecionados e deletados ou copiados. Seleções copiadas podem ser editadas independentemente, rotacionadas e agrupadas ao gráfico quantas vezes necessário.

O software possui um editor de padrões que permite criar pequenos padrões e inseri-los uma ou múltiplas vezes em qualquer padrão. Ao definir a área de trabalho o software permite o uso de grid circular, retangular ou a combinação entre eles. No modo circular o software não oferece opções automatizadas uma vez que ele não prevê onde o próximo ponto vai ser posicionado, porém, existe a possibilidade de posicionar um número de pontos idênticos definido pelo usuário ao longo de uma carreira. No modo retangular, o software permite que vários blocos sejam posicionados automaticamente ao longo da linha criando assim uma possibilidade de automação de tarefas repetidas. Apesar dessas duas últimas características permitirem um trabalho automatizado, grande parte das funções do software requer repetição de comandos acionados pelo clique do mouse. A versão analisada neste texto foi a versão demo do software. Os desenvolvedores disponibilizam outras duas versões comerciais que oferecem ao usuário upgrades de interface e outras funções que não impactam diretamente o processo de desenvolvimento do padrão.

\section{Relações entre a Criatividade Computacional e Humana no desenvolvimento de doilies}

Criatividade computacional é um amplo campo de pesquisa que envolve o uso de computação em processos criativos de poéticas, incluindo também campos interdisciplinares do Design, Arquitetura e Música. Dos processos criativos emergem estruturas que por vezes são avaliadas a partir de suas qualidades composicionais, no entanto, este artigo não entrará na discussão de valorização estética desses processos criativos. Aqui, abordamos os processos criativos enquanto emergências de sistemas de interações entre partes. Para efeito didático, também abordamos três fases distintas dos processos de criatividade computacional, a aplicação de algoritmos generativos randômicos, generativos e comportamentais a partir de uma perspectiva biológica (McCormack, 2019).

Importante ressaltar que na área de criatividade computacional a automação do processo criativo não é o objetivo, uma vez que a codificação e desenvolvimento desses sistemas trabalha em conjunto com as intencionalidades propostas pela poética, em um ecossistema de retroalimentação entre a geração de propostas, a modificação de lógicas criativas e a validação das emergências estabelecidas. No caso do crochê, a geração das possibilidades criativas computacionais estão limitadas também a produção de uma fase específica do processo, o desenvolvimento do padrão visual gráfico dos símbolos que representam pontos do crochê. Dentro deste processo, a concretização da peça física é desenvolvida pelo artesão e existe uma 
enorme quantidade de tomadas de decisão que estão ao critério das condições de fabricação física da peça. Entendemos essa dinâmica de geração de padrões, escolha e fabricação como uma estrutura sistêmica diversa, onde dois sistemas distintos trabalham em conjunto na criatividade dos doilies.

Retornando os procedimentos de criatividade computacionais: randômico, generativo e comportamental, estes representam três níveis dissemelhantes de tomadas de decisão, onde é possível observar uma graduação de autonomia ao processo computacional em cada uma das propostas descritas. Independente do grau de autonomia, a criatividade computacional incorporada a geração de doilies acelera o processo de geração de alternativas possíveis, portanto torna-se essencial a aplicação de um mecanismo de seleção. Em uma perspectiva biológica, a seleção e a geração de alternativas são partes essenciais no ecossistema criativo, uma vez que estabelecem quais sobrevivem e quais serão realmente concretizadas. No primeiro nível de criação randômica, a lógica de geração de alternativas é aleatória, e não segue nenhum padrão intencional ou poético, e fica a cargo do artesão a escolha das peças a partir de um critério estabelecido por ele.

Com os algoritmos generativos, a lógica poética pode ser estabelecida por meio de regras simples incorporadas aos elementos básicos da criação das peças, os pontos do crochê. Esta lógica permite possibilidade de formas emergentes de design, uma vez que são sistemas dinâmicos e portanto carregam consigo os princípios básicos fundamentais sobre esses sistemas: o comportamento randômico pode emergir de sistemas determinados sem uma interferência externa randômica; o comportamento de um sistema determinístico não pode, a princípio, ser previsto em um longo tempo devido à dependência das condições iniciais; apesar de não ser possível prever o comportamento de sistemas caóticos, existe uma ordem no caos: a bifurcação e as constantes de Feigenbaum . Nesse momento, o artesão trabalha de forma mais agregada ao sistema de criatividade computacional, onde ele pode estabelecer as lógicas internas dos pontos, e selecionar padrões reconhecíveis por estas lógicas.

Por fim, a inclusão de um comportamento intencional aos pontos do crochê permite ao artesão o desenvolvimento de uma poética onde a programação em si se torna um alicerce de linguagem. Segundo Pearson (2011), podemos criar agentes computacionais simulando sentimentos, aspirações, falhas e destinos, eles podem ser cidadãos ativos em um mundo virtual, embora altamente abstrato. McCormack (2019), descreve de forma ainda mais enfática que esses agentes devem organizar-se em termos de condições ambientais e recursos, que determinarão a distribuição e abundância desses organismos. As condições estabelecem uma relação com a seleção natural, e coincidem com um grau de incerteza onde os eventos ambientais modificam as condições de seleção, que por outro lado servem de estímulo ao comportamento dos agentes. McCormack argumenta que os processos de ecossistema reconhecem um importante vínculo entre estrutura e comportamento, e afirma que esse processo de emergência de complexidade "permitem ao humano expandir potencialmente sua criatividade, em vez de subsumir e homogeneizar" (2019, p. 348). 
A inclusão de comportamento criativo computacional aos pontos do crochê, estabelece uma relação de convivência entre o artesão e o sistema de geração de padrões, onde o artesão é parte integrante no desenvolvimento das intencionalidades dessa ecologia sistêmica, e ao mesmo tempo estabelece com ela relações de interação que produzem emergência de padrões gráficos visuais. Essas composições são autônomas (Marinho; Bergamo, 2014), estabelecem dentro de si um nível de organização composicional, mas para que sobrevivam a entropia, devem estabelecer padrões de relacionamento ao ambiente, que é alterado e modificado pelo artesão. Nesse sentido, o objetivo desse trabalho é mostrar a tendência a criatividade computacional enquanto um modelo biológico, pois ela é capaz de incorporar consigo a poética onde a estética não pode ser desassociada da repetição, valorizando a delicadeza das pequenas transformações (Bergamo; Marinho, 2016).

\section{Aplicação de Algoritmos Randômicos e Generativos e proposição de um modelo comportamental de agenciamento}

Organizamos essa parte do artigo para demonstrar três diferentes formas de potencialidades da aplicação de criatividade computacional no desenvolvimento dos doilies em crochê. $\mathrm{O}$ uso da lógica randômica simples, o uso de um algoritmo generativo, e por fim a proposição de um modelo de inteligência comportamental aos pontos dos doilies, desta última proposta, não temos ainda os dados resultantes da aplicação da criatividade computacional, mas a proposta do modelo direciona o desejo de futuras investigações para a área.

\section{Lógica Randômica}

Na primeira etapa de experimentação criamos um código randômico de geração de doilies com pontos localizados em espaço aleatório. Essa primeira etapa foi significativa para o desenvolvimento da lógica de construção do objeto de estudo. Na prática de crochê, de acordo com a peça a ser confeccionada a quantidade de pontos diferentes pode variar. Geralmente pontos mais complexos são a junção de pontos básicos como o ponto pipoca que é a junção de cinco pontos altos. A experimentação deste artigo trabalhou com pontos básicos na construção do código: ponto correntinha; ponto baixíssimo; ponto baixo e ponto alto.

No crochê físico, o ponto correntinha é o ponto base para iniciar uma peça ou mudar a direção de uma peça existente, além de poder ser utilizado como elemento independente. $O$ ponto baixíssimo faz com que a agulha avance sem deixar que o tecido fique muito alto, devido a essa propriedade ele é comumente utilizado para acabamentos de círculos e para finalização das carreiras em peças circulares. Também é possível fazer uma 
carreira inteira com esse ponto ao redor de uma borda para dar acabamento. $O$ ponto baixo possui altura e largura proporcionais. $O$ ponto alto é alto o bastante para passar por cima de uma carreira feita de pontos baixos e alcançar a carreira anterior, ou deixar um espaço maior.

Para a criação do algoritmo de lógica randômica, foram utilizados parâmetros fixos de distância da primeira carreira, distância entre as carreiras, e quantidade de pontos por carreira. Nesse algoritmo estabelecemos o limite de sete carreiras para o estudo das qualidades gráficas das imagens.

$\mathrm{Na}$ Figura 1 podemos observar os códigos produzidos pelo algoritmo randômico, para a geração das alternativas produzidas para este artigo o valor da distância entre as carreiras foi mantida sem alteração (50 pontos), para melhor observação de padrões. Foram alteradas as quantidades de pontos por carreira e o raio inicial da primeira carreira, com apenas essas duas alterações e apenas três testes de cada alternativa, é possível analisar o potencial de diferentes estruturas geradas. Nem todas as alternativas são passíveis de serem fisicamente implementadas, mas neste momento do trabalho, havia uma preocupação de investigar o potencial dos valores que podiam ser alterados para a geração das formas. Ainda analisando a figura 1, é possível destacar uma das características mais básicas dos sistemas dinâmicos, a dependência das condições iniciais dos sistemas. Se o sistema inicia-se com muita amplitude entre os pontos (no topo da imagem) ele se torna muito difícil de ser produzido, pois a variação entre os pontos possíveis e a distância entre os mesmos, cria muitos espaços vazios. Da mesma forma, quando a distância entre os pontos é muito pequena (na parte de baixo da figura), a quantidade de pontos pode se tornar muito sobrecarregada, e é preciso investigar a capacidade de se criar fisicamente uma peça como esta. No centro da imagem, temos uma possível condição inicial do sistema, para criar peças finais com seis carreiras. Contudo, o algoritmo randômico pela própria natureza aleatória das trocas não gera padrões discerníveis de composição.
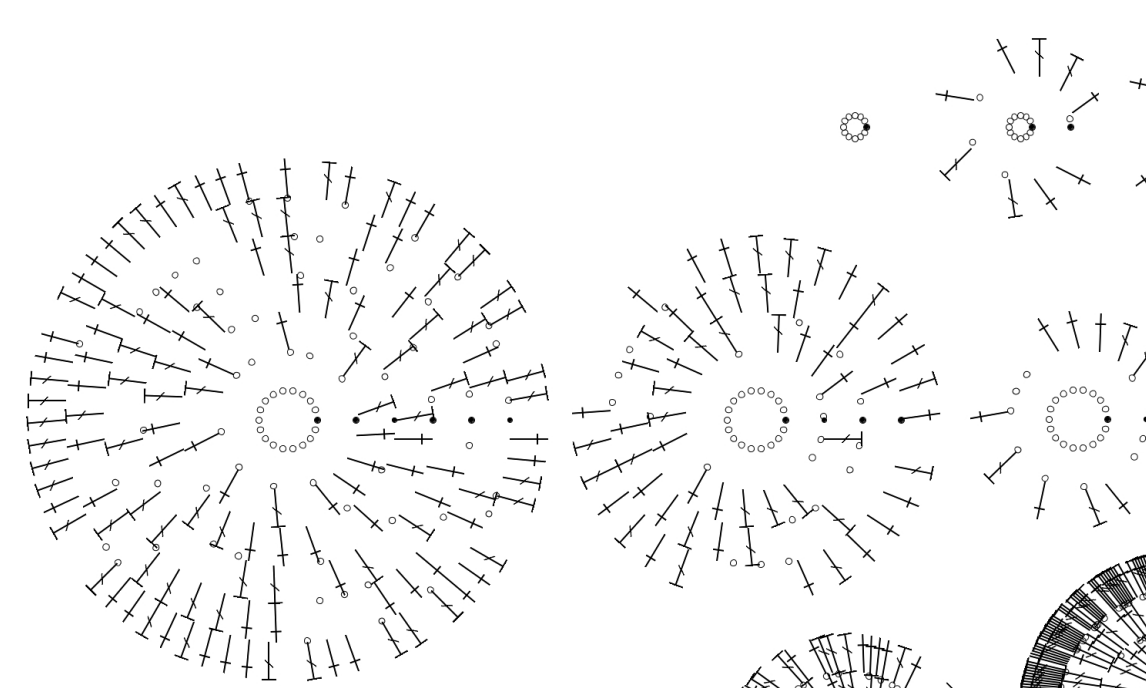
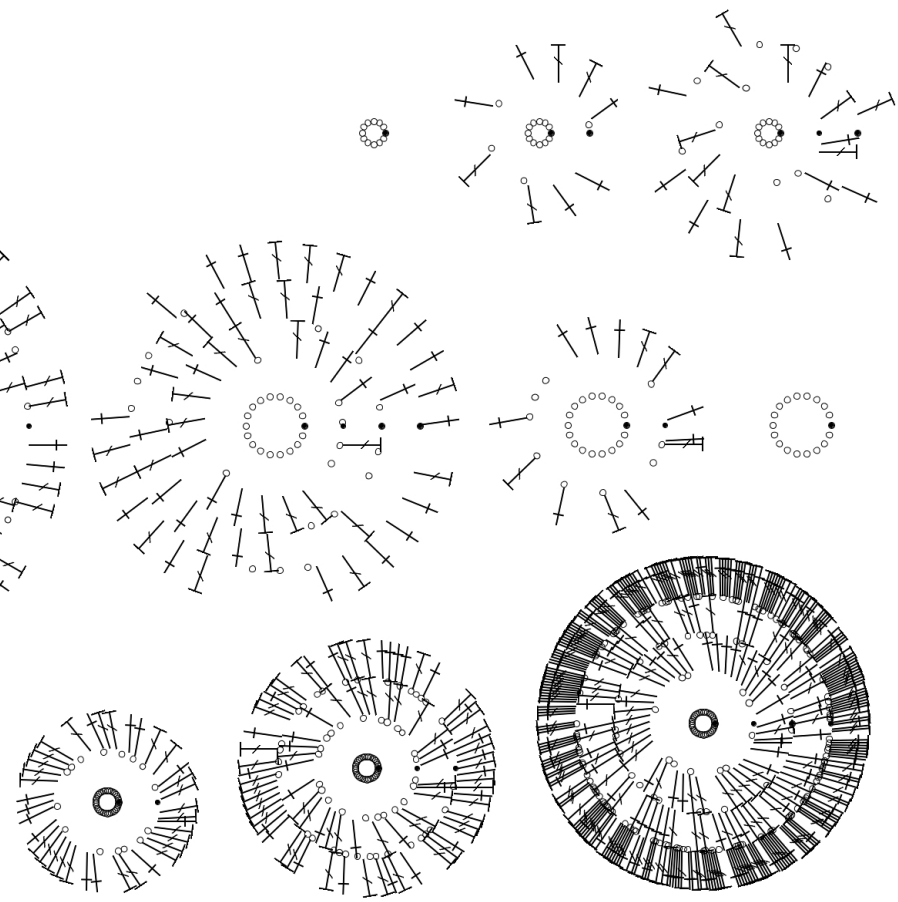

Fig 1. Análise do algoritmo randômico, nestas imagens a carreira central foi destacada do resto das peças para melhor visualização das condições iniciais do sistema.

Fonte: Os autores, 2020 


\section{Lógica Generativa: Autômatos Celulares}

Os algoritmos randômicos são composições complexas, são sistemas de estruturas paralelas, onde sua interação faz com que emerjam comportamentos resultantes da ação coletiva. No caso dos algoritmos generativos, geralmente os relacionamentos entre as partes são de curto-alcance, chamadas reações reativas, sem uso de memória. A base para o estudo dessa segunda etapa foi o uso de autômatos celulares (CA), pois neste trabalho o que interessa não são as forças de locomoção sobre a composição que alteram a visualização dos pontos (como em um comportamento de bando), mas a escolha do tipo de ponto de crochê de acordo com uma relação entre outros pontos do sistema.

Como a análise de todos os pontos do sistema demanda muito recurso de computação estabelecemos uma lógica que dialoga com o com o conceito do Jogo da Vida de John Conway, onde estabelecemos uma vizinhança (figura 2) onde o ponto irá observar os estados dos outros para tomar uma decisão de escolha de quem ele vai se tornar. Essa vizinhança pode ser parametrizada pelo código, e podemos trabalhar com todo o doilie como uma vizinhança única, ou dividindo o espaço pelo número de vizinhanças desejadas. Claro que há um limite, um número muito alto de vizinhas não fará sentido para a divisão das partes do doilie.

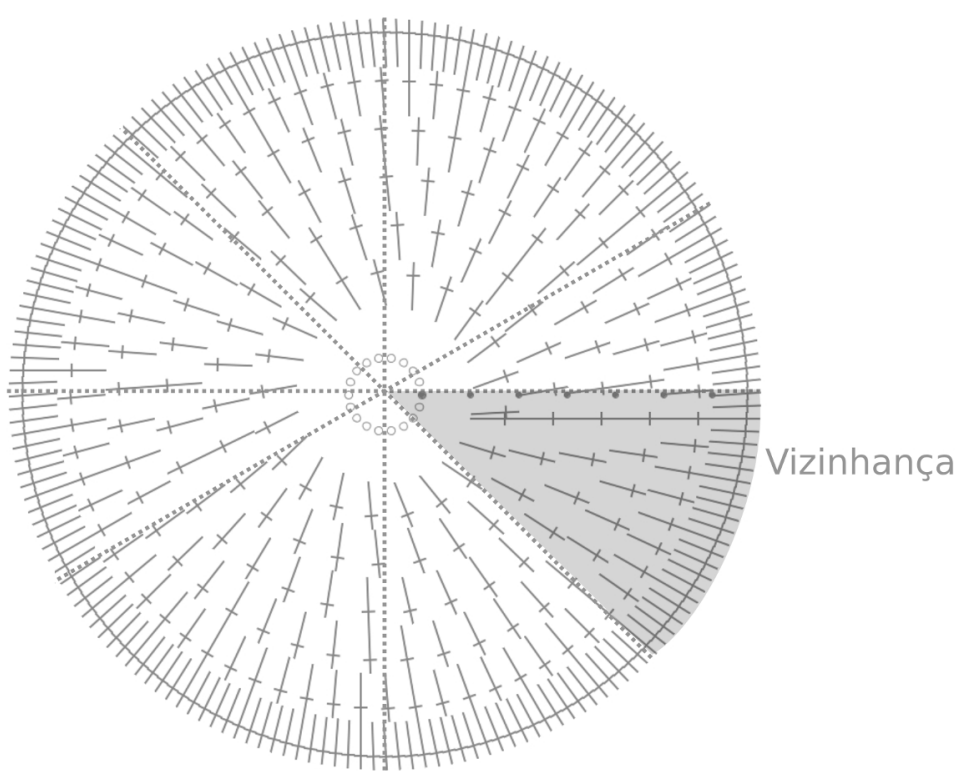

Fig 2. Lógica Generativa - Conceito de Vizinhança Fonte: Os autores, 2020

Assim como no Jogo da Vida de John Conway, os pontos devem escolher um estado, mas trabalhamos com três estados ao invés de dois, um ponto pode escolher entre ser correntinha, ponto baixo ou ponto alto, essa decisão depende da seguinte lógica: 
- Correntinha: se o número de vizinhos como ponto alto ou baixo é maior que $3 / 4$ da vizinhança;

- Ponto baixo: se o número de pontos correntinhas é menor que $1 / 3$ da vizinhança;

- Ponto alto: se a soma de pontos correntinha e pontos baixo é maior que a $1 / 2$ da vizinhança;
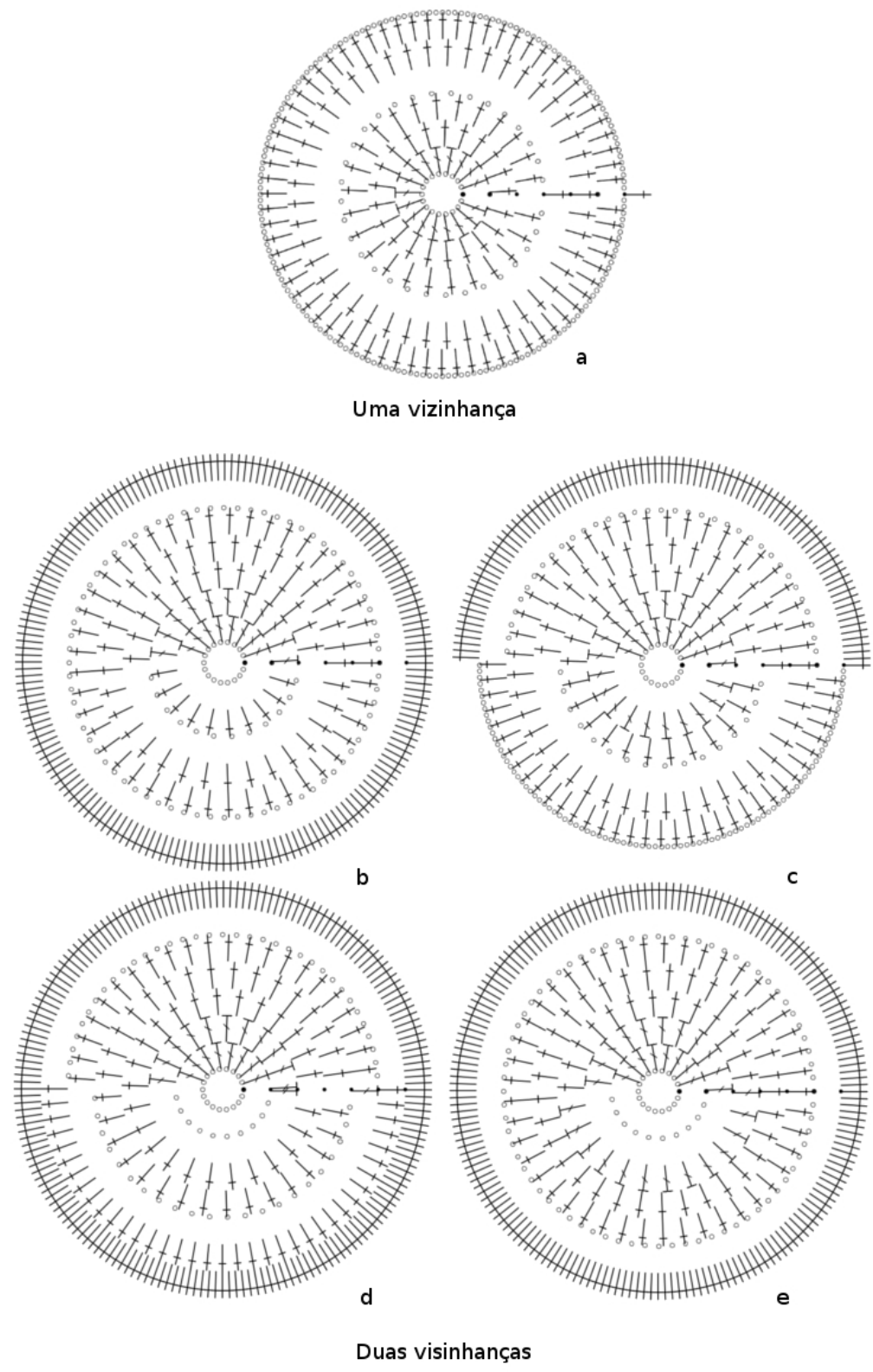

Fig 3. Padrão Observado para uma e duas vizinhanças Fonte: Os autores, 2020
Esta lógica apresentada foi criada de maneira experimental, e os autores estão em processo de investigação de lógicas para o desenvolvimento de padrões generativos. Entretanto, ela demonstra o potencial de geração de padrões a partir da inclusão de criatividade computacional. $\mathrm{Na}$ figura 3 , são apresentados os padrões gerados para códigos com uma e duas vizinhanças. No caso de apenas uma vizinhança (3a) o código apresenta sempre o mesmo padrão para oito carreiras, que ao final de alguns ciclos de vida acaba sempre com a segunda carreira de pontos altos, terceira e quarta de pontos baixos e quinta carreira de correntinha, então novamente duas carreiras de ponto baixo e uma carreira de correntinha. Ainda na Figura 3 , temos o comportamento generativo para duas vizinhanças, esta configuração apresentou sempre um total de quatro $(3 b, 3 c, 3 d$ e 3e) padrões que alternavam-se na primeira vizinhança, enquanto a segunda vizinhança nunca era alterada.

$\mathrm{Na}$ figura 4, apresentamos o resultado para o caso de quatro vizinhanças, e novamente a última vizinhança se mantém inalterada não gerando nenhum padrão. Contrariamente, o primeiro, segundo e terceiro quadrante apresentaram padrões diferenciados de quando houve somente duas vizinhanças (4f - primeiro quadrante). Mas também o primeiro, segundo e terceiro quadrante apresentaram padrões similares ao que ocorria com apenas duas vizinhanças (4g - primeiro quadrante). 


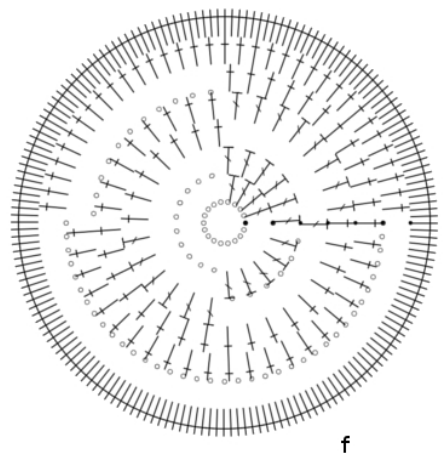

Fig 4. Padrão Observado para quatro vizinhanças Fonte: Os autores, 2020
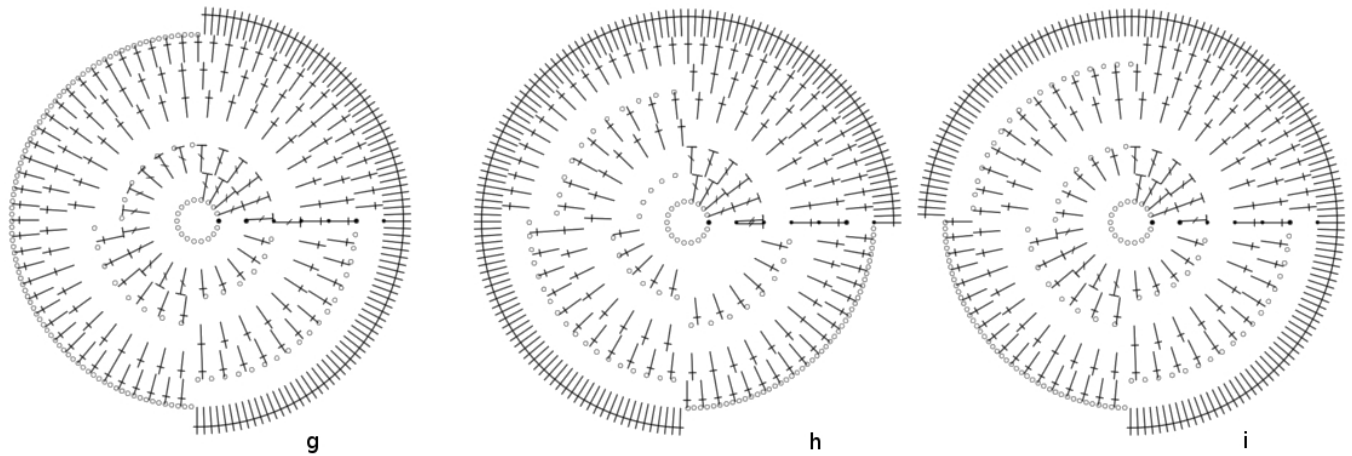

Quatro visinhanças

Apesar do potencial dos padrões encontrados nas figuras 3 e 4 , os pesquisadores acreditam que não foram ainda realizados testes suficientes para que se possa argumentar conclusivamente sobre a relação número de vizinhanças e padrões observados, restando para futuras investigações alguma afirmação sobre a lógica descrita acima. $O$ objetivo dessa experimentação não foi criar uma série de padrões observáveis como no caso do Jogo da Vida, mas sim a validação da lógica do autômato celular como potencial de criatividade computacional.

\section{Comportamento criativo social: agentes Inteligentes}

Acreditamos que o aumento da autonomia da criatividade computacional é fundamental para o desenvolvimento de pesquisas sobre a geração de padrões de doilies mais complexas. Este terceiro nível de inclusão de autonomia, ainda não foi implementado pelos autores, mas pode ser descrito como um comportamento intencional do ponto de crochê que simula sentimentos, aspirações, falhas e destinos. Esse conceito se traduz na narrativa de um conceito de existência aos agentes computacionais, a este agente é preciso incluir situações de nascimento, reprodução e seleção natural dentro do sistema de geração dos doilies. Outro ponto fundamental seria a geração de um comportamento autocrítico por parte do próprio ponto de crochê, para que estabelecesse parâmetros de inclusão de julgamento sobre as próprias escolhas desenvolvidas. Propõe-se então o desenvolvimento de um agente computacional segundo Bergamo (2015) no modelo C+ (Figura 5) para ser incluído a classe de pontos do sistema de padrões de doilies. 
Este modelo de agente é capaz de trabalhar o conceito de criatividade computacional, desenvolvendo um agente inteligente com sentimentos, memória, e criatividade assim como descrito por Pearson (2011). 0 agente $\mathrm{C}+$ como ponto de um doilie é um agente que, por estabelecer um pensamento criativo, coincide com o grau de incerteza onde os eventos ambientais modificam as condições de seleção natural (McCormack, 2019).

\author{
s: Camada Sensivel \\ P: Camada de Percepçâo \\ a: Camada Atuadora \\ A: Camada de Ação \\ MCD: Memória de Curta Duração \\ $\mathrm{C}_{1}$ : Concepção (tomada de decisâo) \\ C2: Curiosidade \\ I: Inovação \\ N: $\quad$ Novidade \\ C3: Conduta Cultural \\ I1: Imitação \\ A: $\quad$ Aprendizado \\ MLD: Memória de Longa Duraçăo \\ M1... Mn: Módulos Computacionais de \\ 1 a n, (Lei do Relaxamento)
}

Fig 5. Arquitetura Agente C+

Fonte: Bergamo, 2015, p. 149.

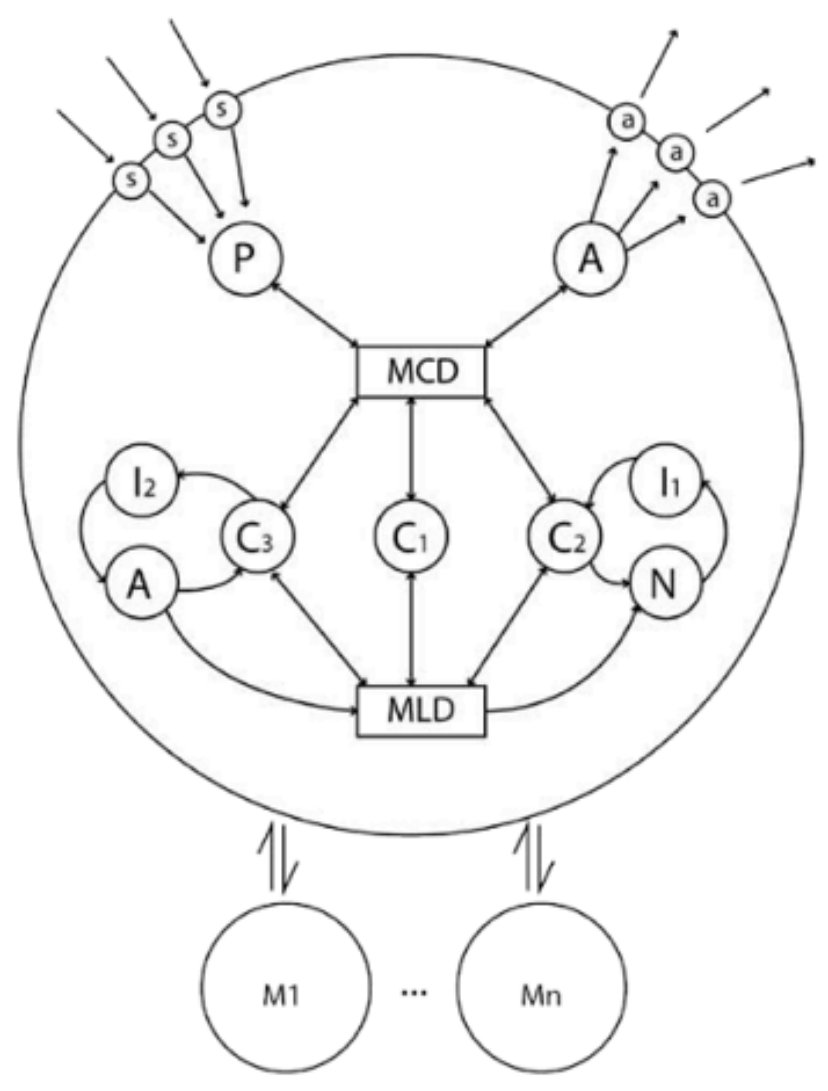

Arquitetura Agente C+ 


\section{Potencialidades de Design}

O desenvolvimento do crochê é uma atividade criativa, ela se desenvolve na prática do artesão, na observação e repetição de padrões. A emergência de novos padrões é uma realidade sistêmica, e portanto é dependente das relações complexas que envolvem a autonomia dos agentes em questão, assim como a capacidade criativa destes. A inclusão da criatividade computacional a esse sistema cria uma outra camada de agentes, e consequentemente aumenta a complexidade do sistema, gerando novos padrões observáveis.

Apenas com o primeiro nível de autonomia desses agentes, dando ao computador a liberdade de gerar pontos de forma randômica sobre o sistema, já observamos um número de geração de alternativas muito amplo. Entretanto, fica demasiadamente custoso ao artesão a seleção dos padrões a partir de pontos aleatórios sobre as peças do doilies. Não obstante, é importante ressaltar que a aleatoriedade é muitas vezes um elemento evocativo e significativo na arte (Krokatsis et al, apud McCormack, 2013, p. 5). Quando aumenta-se autonomia criativa computacional, a exemplo da inclusão de autômatos celulares, comprova-se a existência de complexidade por meio do aparecimento dos padrões. 0 exemplo de autômatos celulares também apresenta claras características dos sistemas complexos como as bifurcações, pois quando dobra-se a quantidade de vizinhanças aumenta-se o número de padrões observáveis. Além disso, se as vizinhanças chegam a ponto de ficarem muito pequenas o resultado visual torna-se caótico. Por fim, defendemos o aumento da autonomia computacional com a inclusão do agente $\mathrm{C}+$ como forma aumentar o potencial criativo da máquina. Conforme McCormack (2013), a simulação desses modelos de comportamento de arte evolutiva são experimentos filosóficos, independentemente de sua relação com as questões da estética (enquanto filosofia da arte). Possuem "o potencial de iluminar compreensões sobre a cultura, as manias, a moda - até a arte e o mundo da arte em si” (p. 10). Portanto, acreditamos que a implementação de agentes comportamentais vai de encontro ao potencial criativo sistêmico apresentado nesse artigo.

Este estudo demonstrou que os softwares digitais disponíveis, até o momento da escrita deste documento, de nada podem acrescentar ao desenvolvimento da criatividade de doilies. Eles são ferramentas que podem acelerar o potencial criativo do artesão, mas não permitem ao humano expandir potencialmente sua criatividade. A inclusão de diferentes níveis de autonomia computacional é capaz de agregar ao sistema de geração de doilies distintas complexidades que estendem o nível da relação homem com a ferramenta digital, para uma de agenciamento entre sistemas dissemelhantes. 


\section{Referências}

BALL, P. The Self-Made Tapestry: Patterns formation in nature. Oxford: Oxford University Press. 1999.

BERGAMO, M. L.; MARINHO, F. C. C. . Tecnologia e Delicadeza: estratégias da simplicidade cotidiana na geração de resultados estéticos complexos. In: Cleomar Rocha e Suzete Venturelli. (Org.). Mutações, confluências e experimentações na Arte e Tecnologia. 1ed.Brasília: PPG-ARTE/UNB, 2016, v. 1, p. 141-153.

BERGAMO, M. Interação sistêmica em arte computacional: a-memory garden uma proposta prática e teórica de pesquisa estética. 2015. 180 f., il. Tese (Doutorado em Artes)-Universidade de Brasília, Brasília, 2015.

CHOMA, J. Morphing: A Guide to Mathematical Transformations for Architects and Designers. London : Laurence King Publishing, 2015.

IWAMOTO, L. Digital fabrications architectural and material techniques. Nova Iorque: Princeton Architectural Press, 2009.

KANAGY-LOUX, E.; MILLS, A.; NEFF, N. Lace, not Lace: Contemporary Fiber Art from Lacemaking Techniques. New Jersey: Hunterdon Art Museum, 2019.

KENNING, Gail Joy. Process: An aesthetic exploration of the digital possibilities for conventional physical lace patterns. (Tese de Doutoramento). University of New South Wales, Australia, 2007.

MCCORMACK, J. Creative Systems: A Biological Perspective. Em: T. Veale, F. A. Cardoso (eds.), Computational Creativity, Computational Synthesis and Creative Systems. Switzerland: Springer Nature, 2019.

MCCORMACK, J. Art, Aesthetics, Evolution em P. Machado, J. McDermott \& A. Carballa (eds) Proceedings of EvoMUSART 2013, Vienna, Austria 3-5 April., Springer, Berlin; Heidelberg. pp. 1-12, 2013.

MARINHO, F. C. C. BERGAMO, M. L.; Do elemento autônomo à composição autônoma. Texto Digital, Santa Catarina, p. 227 - 247, 27 ago. 2013.

PEARSON, M. Generative art : A practical guide using processing. Shelter Island, NY : London: Manning ; Pearson Education [distributor], 2011.

SHIFFMAN, D. Cellular Automata. In: The Nature of Code, 2020. (https://natureofcode. com/book/chapter-7-cellular-automata/)

WANNAMAKER, K.; OEHLBERG, L.; CARPENDALE, S.; WILLETT, W. Data Embroidery: Exploring Alternative Mediums for Personal Physicalization (conference poster), disponível em <https://prism.ucalgary.ca/bitstream/handle/1880/110218/DataEmbroidery.pdf?sequence=1\&isAllowed=y> Acesso em 05 de fevereiro de 2020 . 